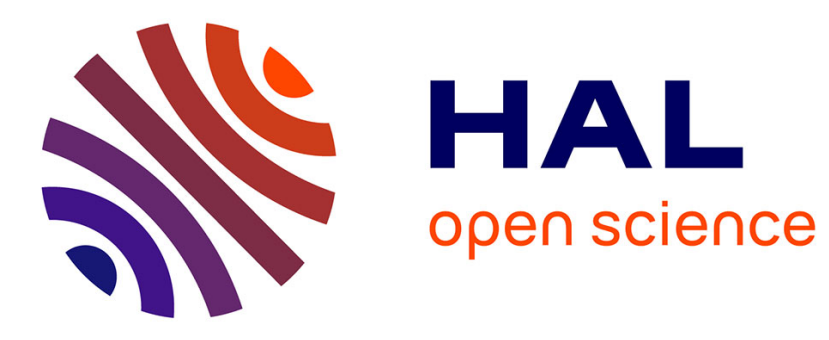

\title{
Ways in which engaging in someone else's reasoning is productive
}

Chris Rasmussen, Naneh Apkarian, Tommy Dreyfus, Matthew Voigt

\section{To cite this version:}

Chris Rasmussen, Naneh Apkarian, Tommy Dreyfus, Matthew Voigt. Ways in which engaging in someone else's reasoning is productive. First conference of International Network for Didactic Research in University Mathematics, Mar 2016, Montpellier, France. hal-01337893

\section{HAL Id: hal-01337893 \\ https://hal.science/hal-01337893}

Submitted on 27 Jun 2016

HAL is a multi-disciplinary open access archive for the deposit and dissemination of scientific research documents, whether they are published or not. The documents may come from teaching and research institutions in France or abroad, or from public or private research centers.
L'archive ouverte pluridisciplinaire HAL, est destinée au dépôt et à la diffusion de documents scientifiques de niveau recherche, publiés ou non, émanant des établissements d'enseignement et de recherche français ou étrangers, des laboratoires publics ou privés. 


\title{
Ways in which engaging in someone else's reasoning is productive
}

\author{
Chris Rasmussen ${ }^{1}$, Naneh Apkarian ${ }^{1}$, Tommy Dreyfus ${ }^{2}$, and Matthew Voigt ${ }^{1}$ \\ ${ }^{1}$ San Diego State University, United States, chris.rasmussen@sdsu.edu, ${ }^{2} T e l$ Aviv \\ University, Israel
}

Typical goals for inquiry-oriented mathematics classrooms are for students to explain their reasoning and to make sense of others' reasoning. In this paper we offer a framework for interpreting ways in which engaging in the reasoning of someone else is productive for the person who is listening. The framework, which captures the relationship between engaging with another's reasoning, decentering, elaborating justifications, and refining/enriching conceptions, is the result of analysis of 10 individual problem-solving interviews with 10 mathematics education graduate students enrolled in a mathematics content course on chaos and fractals. The theoretical grounding for this work is that of the emergent perspective (Cobb \& Yackel, 1996).

Keywords: Decentering, Argumentation, Social Norms, Fractals, Paradox.

\section{INTRODUCTION}

Typical goals for inquiry-oriented mathematics classrooms are to foster particular social norms, such as students explaining their reasoning, listening to others' reasoning, and making sense of that reasoning (Yackel \& Cobb, 1996). Indeed, such goals for student participation have been central to a long line of recommendations in the United States (National Council of Teachers of Mathematics, 2000; National Governors Association Center for Best Practices \& Council of Chief State School Officers, 2010). The purpose of this paper is to offer a framework for understanding the various ways in which engaging in the reasoning of someone else is productive for the person who is listening to and attempting to make sense of this reasoning. Prior research has documented ways in which teachers can initiate and sustain such norms for participation (e.g., Lampert, 1990; Stephan \& Whitenack, 2003), but most research into the benefits of such engagement focuses on the students' thinking, not that of the one engaging in the other's reasoning (e.g., Teuscher, Moore, \& Carlson, 2015). While there has been some research into mutual intellectual benefit stemming from peer-to-peer engagements (e.g., Kieran \& Dreyfus, 1998), it has not been at the collegiate level. Our work contributes to this surprisingly sparse literature, extends notions identified in disparate settings, and adds nuance to existing notions of engaging and decentering.

The theoretical grounding for this work is that of the emergent perspective (Cobb \& Yackel, 1996), which coordinates the individual cognitive perspective of constructivism (von Glasersfeld, 1995) and the sociocultural perspective based on symbolic interactionism (Blumer, 1969). A primary assumption from this point of view is that mathematical progress is a process of active individual construction and a process of mathematical enculturation. The interpretive framework, shown in Figure 
1, lays out the central constructs in the emergent perspective. The within row relationships between respective collective and individual constructs is said to be reflexive, meaning that they are mutually constitutive, evolving together in a dynamic system. For example, Yackel and Rasmussen (2002) analyze individual students' evolving beliefs about their and others' role in relation to evolving classroom social norms. This work speaks to one way in which engaging in the reasoning of others (a social norm) is productive for the individual; namely doing so positively shapes beliefs.

\begin{tabular}{|l|l|}
\hline Collective Perspective & Individual Perspective \\
\hline Classroom social norms & $\begin{array}{l}\text { Beliefs about own role, others roles, } \\
\text { and the general nature of mathematical } \\
\text { activity }\end{array}$ \\
\hline Sociomathematical norms & Mathematical beliefs and values \\
\hline Classroom mathematical practices & Mathematical conceptions and activity \\
\hline
\end{tabular}

\section{Figure 1: The interpretive framework}

In furthering the relationships between the constructs in Figure 1, we argue for across row relationships. In particular, we take the stance that classroom social norms are also inextricably intertwined with individual mathematical conceptions and activity. In so doing we make an empirically grounded argument for a theoretical connection between the upper left hand cell of the interpretive framework and the bottom right hand cell.

In our broader research program (Hershkowitz, Tabach, Rasmussen, \& Dreyfus, 2014; Tabach, Rasmussen, Hershkowitz, \& Dreyfus, 2015), we are investigating the coordination between individual and collective processes. In this report, however, we focus on analyzing individual mathematical conceptions and activity in an individual interview setting, with the subsequent goal of coordinating this analysis with an analysis of classroom video-recordings. This report lays a foundation for this subsequent analysis, but the framework for ways of engaging in someone else's reasoning is potentially significant on its own.

\section{METHODOLOGY}

The methodological approach for the larger study falls under the genre of "designbased research" (Cobb, 2000; Design-Based Research Collective, 2003). The study took place in an intact graduate level mathematics course about chaos and fractals with 11 students (10 of whom agreed to participate in individual interviews). Students were (or intended to be) secondary school teachers or community college instructors and all had a bachelor's degree in mathematics. Their masters degree program required a substantial component of mathematics, and the chaos and fractals course qualified as one of their mathematics courses. The course was taught by one of the research team members. Data collected as part of the larger study included video- 
recordings of each class session, individual problem solving interviews conducted at the middle and end of the semester, and copies of all student work. In this paper we report on an analysis of the 10 individual, mid-semester problem-solving interviews.

The following question from the mid semester interview is the focus of this analysis:

In class, we discussed the Sierpinski Triangle. How do you think about what happens to the perimeter and the area of the Sierpinski Triangle as the number of iterations tends to infinity?

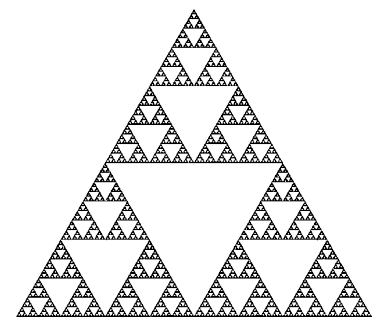

Follow-up questions:

a. One a scale from 1 to 10 with 10 being the most confident, how confident are you about what happens to the area? Can you say more about why you said [confidence number]?

b. On a scale from 1 to 10 , with 10 being the most confident, how confident are you about what happens to the perimeter? Why do you say [confidence number]?

c. A student named Fred claimed the following. Please read it out loud. What do you think about his argument? (Please explain)

Fred's Argument: The computation shows that the perimeter goes to infinity because the perimeter is given by $3 \times\left(\frac{3}{2} / 2\right)^{\mathrm{n}}$ which increases to infinity as $n$ tends to infinity. But, the perimeter can't really be infinitely long, because there is nothing left to draw a perimeter around, since the area goes to zero.

The Sierpinski Triangle is a fractal, and is the result of an infinite iterative process that begins with an equilateral triangle. Connecting the midpoints of its sides results in another equilateral triangle with sides half the length of the original's and area that is one-fourth of the original's, which is then removed. Repeating this process, ad infinitum, results in the Sierpinski Triangle. At each step of the process, the area of shrinks by a factor of $3 / 4$ and the perimeter grows by a factor of $3 / 2$. The perimeter of the Sierpinski Triangle can be described by the limit, as $\mathrm{n} \rightarrow \infty$, of $\mathrm{P}_{0} \times(3 / 2)^{\mathrm{n}}$, and the area by the limit, as $\mathrm{n} \rightarrow \infty$, of $\mathrm{A}_{0} \times(3 / 4)^{\mathrm{n}}$, where $\mathrm{P}_{0}$ and $\mathrm{A}_{0}$ refer to the perimeter and area of the starting triangle. Thus the Sierpinski Triangle has a perimeter of infinite length and an area of zero. This apparent contradiction comes from the fact that it is a fractal with Fractal dimension $\log _{2}(3)$, putting it between one- and two-dimensions. 
The question was structured so that we would first gain insight into students' own reasoning about the area and perimeter of the Sierpinski triangle, followed by an opportunity for them to engage in the hypothetical reasoning of "Fred." The basis for Fred's reasoning was taken from a whole class discussion that took place several weeks before the interview. Thus, Fred's reasoning is authentic to the students and provides an ideal opportunity for us to subsequently coordinate individual and collective analyses.

While most studies of decentering and engagement have involved interactions between two or more people, ours involves one person interacting with the work of another, who cannot respond. While this setup potentially restricts the ability of interviewees to engage with Fred and his argument, it has certain affordances as well. One affordance is that all interviewees reacted to the same statement, allowing us to make direct comparisons. This setup also controls for a variety of other features, such as personal histories, that may influence how people react to each other in face-toface settings.

The transcripts and student work produced during the interview were open coded using methods from grounded theory (Strauss \& Corbin, 1998). This open coding, which was initially conducted by the first two authors then vetted by the other authors to minimize bias and ensure interpretations were grounded in the data, was informed by literature on student thinking about infinity, and in particular infinite iterative processes (Núñez, 1994; Mamolo \& Zazkis, 2008), but did not rely on an a priori coding scheme.

The open coding of these interviews revealed differences between students' initial responses and those that followed reading Fred's argument. It also revealed a variety of ways of engaging and responding to Fred. We then supplemented our initial coding, using Toulmin's argumentation scheme (Toulmin, 1969) to analyze the preand post-Fred arguments presented by the students. Finally, each transcript was distilled into an argumentation $\log$ (Rasmussen \& Stephan, 2008), coupled with the primary ways of reasoning being used in each argument and instances of engagement, and supplemented by statements about the mathematics that were not necessarily part of a coherent argument. Logs were analyzed for shifts and relationships, with coding conducted by the first two authors and vetted by the other authors.

\section{RESULTS}

Our analysis of students' responses revealed that responding to Fred's argument was a productive experience for most students. There was variation across students with regards to both the extent and nature of their engagement and growth, but we note two major categories of productivity that stemmed from an ability to engage in Fred's reasoning and decenter from their own: elaborating justifications and refining/enriching conceptions of particular mathematical ideas. Figure 2 is intended to capture the relationship between engaging with another's reasoning, decentering, elaborating justifications, and refining/enriching conceptions. Specifically, engaging 
with another's thinking can be foundational for (re)engaging with one's own thinking. That is, the act of decentering provided the means for elaborating justifications and refining one's thinking. The intersecting ovals in Figure 2 for these two acts signify the reciprocal relationship between justifying and refining conceptions.

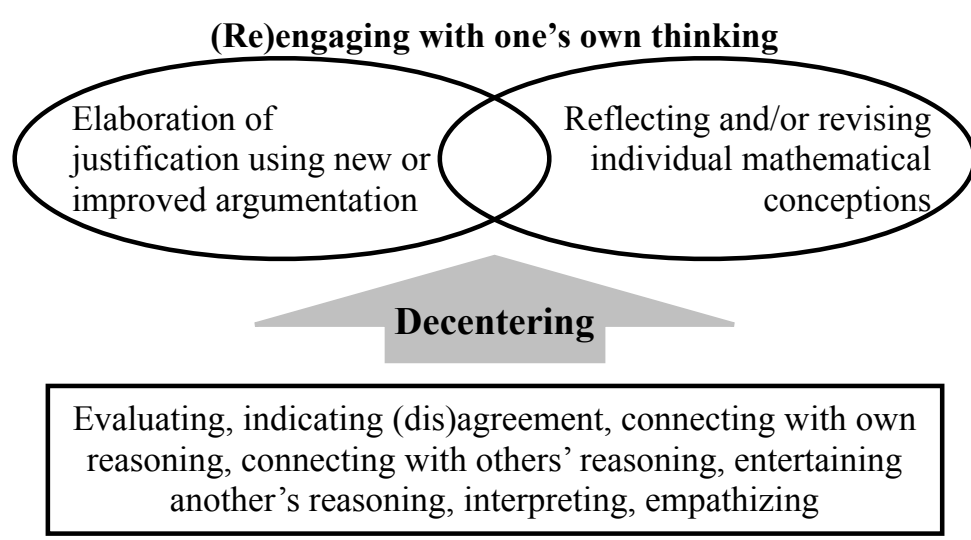

Engaging with another's thinking

\section{Figure 2: Productivity of engaging in another's reasoning}

Since all of the interviewed students were or intended to be teachers at the secondary or postsecondary level, it is particularly interesting to look at their ability to engage with another's thinking. Doing so is foundational to teacher noticing (Jacobs, Lamb, \& Philipp, 2010) in which teachers can instructionally build on student thinking. We found that all of the interviewees exhibited the ability to engage with Fred's thinking. We identified the following ways that interviewees engaged in Fred's reasoning: a) evaluating (with or without justification); b) indicating (dis)agreement (with or without justification); c) making connections to their own reasoning; d) making connections to classmates' reasoning; e) entertaining Fred's reasoning; f) interpreting Fred's reasoning; g) diagnosing Fred's reasoning; and h) empathizing with Fred. These ways of engaging provide an opportunity for the individual to decenter. By decenter, we mean putting aside one's own reasoning in an attempt to understand another's reasoning (Steffe \& Thompson, 2000; Teuscher, Moore, \& Carlson, 2015). Many interviewees, through decentering, engaged or re-engaged with their own thinking in a way that furthered their own thinking. This analysis lays the groundwork for coordinating individual and collective ways of participating in discourse since evaluating (with justification) and indicating (dis)agreement connect strongly to foundational classroom social norms.

In this paper we give a few brief examples of engaging and decentering. Most students gave some indication of agreement or disagreement with Fred's argument, e.g. "I agree with him that the perimeter increases to infinity [...] but I disagree with his second line." This example shows a fairly superficial engagement in which the interviewee attended to Fred's reasoning but viewed it from her own point of view. Other students went further, e.g. "I disagree because we thought about it in terms of 
fencing [...] so eventually it's all fence." The second student's explanation makes it clear that while she has not necessarily built a model of Fred's line of reasoning, she is aware of her own model and believes Fred's is different. This second student then elaborated and improved upon her original argument.

Interviewees also demonstrated a range of depth when engaging with Fred by interpreting his reasoning. Some interpreted Fred's thinking from their own point of view, but others made clear attempts to deduce Fred's reasoning from his point of view - in one case an interviewee requested more information about Fred's argument before settling on an interpretation. We saw evidence, across all interviews, that each act of engaging functioned as a potential stepping-stone to decentering, an opportunity that some students took up while others did not. We saw that students who engaged deeply with Fred's thinking and decentered from their own point of view appeared to (re)engage with their own thinking.

As a consequence of decentering, many of the students clarified and even advanced their own lines of mathematical reasoning as expressed by Figure 2. As Fred's argument was in response to a question they had already answered, many reacted by re-explaining or expanding their initial justification. Within mathematical thinking we observed two main subcategories: the elaboration of justification for their claims and the expansion of their thinking regarding the mathematical concepts involved in the task. By elaboration of justification, we mean that students were observed adding new or improved warrants and backings to strengthen their argument or even providing entirely alternative explanations. As an example, one student, Sandor, reacted to Fred's argument by noting that it is because the area of the Sierpinski Triangle goes to zero that the perimeter goes to infinity, and explicitly connected the removal of triangles at each recursive step to adding the perimeter of these triangles to the total perimeter. Prior to engaging with Fred's statement, he had treated the two results as essentially separate features of the process - the connection between the two had gone unnoticed or at least unexplained.

With regards to the underlying mathematical concepts, we observed students exploring the nature of infinity, perimeter, and the Sierpinski Triangle itself in greater depth than they had in their initial arguments. Some students appeared to become aware of a distinction between potential infinity (the unending process) and actual infinity (the final resultant state) in their attempts to clarify their reasoning. Many students took the opportunity to define, or re-define, the perimeter of an object. Students also reflected on the fractal nature of the Sierpinski Triangle, noting that it exists "between" dimensions and therefore does not act in the way that a "normal" one- or two-dimensional object might, and that therefore traditional thinking about a perimeter enclosing area is not necessarily valid in this context.

While we identify decentering and mathematical thinking as distinct, we note that they are not disjoint. All of these examples of expanded thinking and reasoning occurred to some extent as a reaction to the thinking of someone else. We posit that decentering functioned as a catalyst for this process. Seeing Fred's argument, 
interviewees demonstrated a variety of strategies for engaging with student reasoning, which were taken up with varying depth. Deeper engagement took the form of decentering, which predicated (re)engagement with and growth of their own reasoning. That is to say, the greater the extent to which students engaged with Fred and decentered, the more productive the experience was with regards to their own thinking.

\section{The Case of Curtis}

To clarify the constructs and interpretations outlined above, we present the case of a single student, with pseudonym Curtis. We choose this student as an example because of the brevity and clarity of this portion of his interview, as well as the range of constructs identified in his experience with Fred. Figure 3 shows Toulmin analyses of Curtis's pre- and post-Fred arguments, as well as his comment about infinite processes.
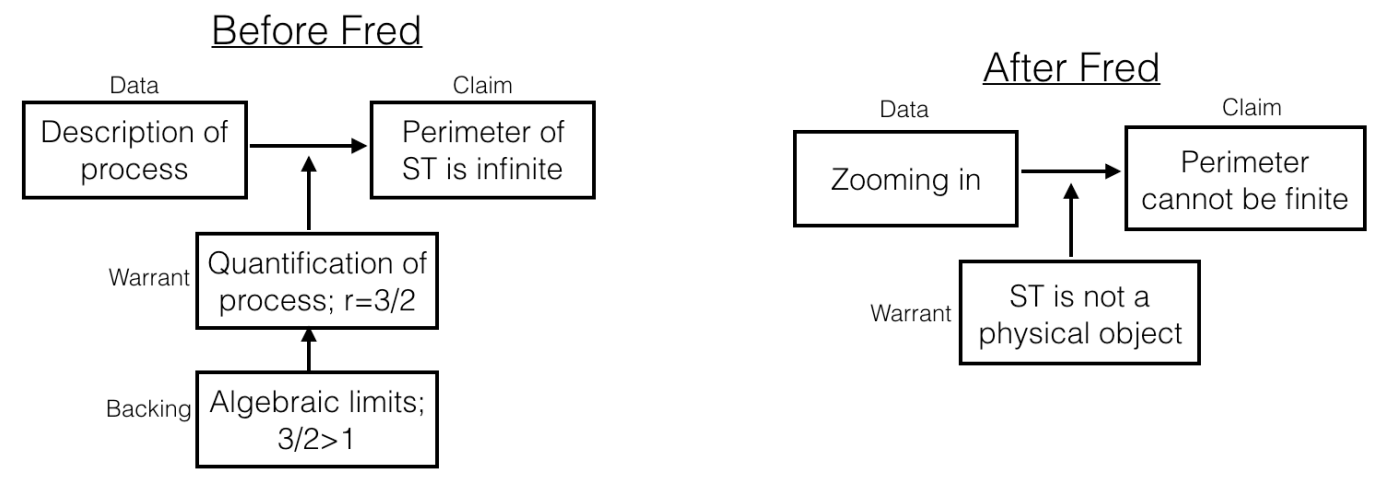

\section{Figure 3: Toulmin analysis of Curtis' arguments.}

Toulmin analysis of Curtis' pre- and post-Fred argumentation revealed shifts and changes. A small shift occurred in Curtis' claim: initially he showed that the perimeter is infinite, afterward he showed it could not be finite. This new claim is drawn from different data and is supported by a different warrant. Where initially Curtis used formal/symbolic reasoning, his second argument draws on heuristics and a sense that the Sierpinski Triangle is not a real object. He also brings up the fact that infinite processes do not have a 'final step' after which they reach their final state, something that was not mentioned prior to Fred.

Retracing the emergence of new topics for Curtis, we found that they were directly linked to his engagement with Fred's reasoning, and in particular resulted from his ability to decenter and look at Fred's reasoning in ways not related to his own. Curtis comments that Fred's "logic doesn't work," addressing more than just his faulty claim. The new warrant that Curtis provides, that the Sierpinski Triangle is not a physical object but rather "kind of just a concept," directly addresses an unspoken assumption on Fred's part. It seems that Curtis has identified and reacted to an implicit backing in Fred's argument - that the Sierpinski Triangle is a geometric object that obeys two-dimensional rules. Curtis' diagnosis of a misconception underlying Fred's reasoning implies that he has considered Fred's argument from a 
different viewpoint, effectively trying to put himself in Fred's shoes and understand fully his reasoning.

In addition to presenting a new argument, Curtis presents it in a new style. While his original argument was based in formal limits and notation, his new argument adopts some of Fred's informal, heuristic, and geometric language. Again, this supports the idea that Curtis is working from Fred's point of view, rather than his own.

Finally, Curtis' added commentary about infinite processes comes from his interpretation of Fred's argument. He says that Fred's argument is equivalent to there being a final step, a point where something is taken away and the area becomes zero, and notes that this is not how infinite processes work. This seems to address Fred's data, that the object becomes something with no area.

Altogether, we see that Curtis addresses all the pieces of Fred's argument (not just the claim) by thinking through Fred's reasoning (not just comparing it to his own). This includes an implicit backing that Fred does not explicitly state. He does so using Fred's style of reasoning, and (re)engages with his own reasoning to present a second argument and an observation about infinite processes. Throughout his response to Fred, Curtis addresses Fred's reasoning and explains why it does not work, rather than simply asserting that his own original ideas are correct.

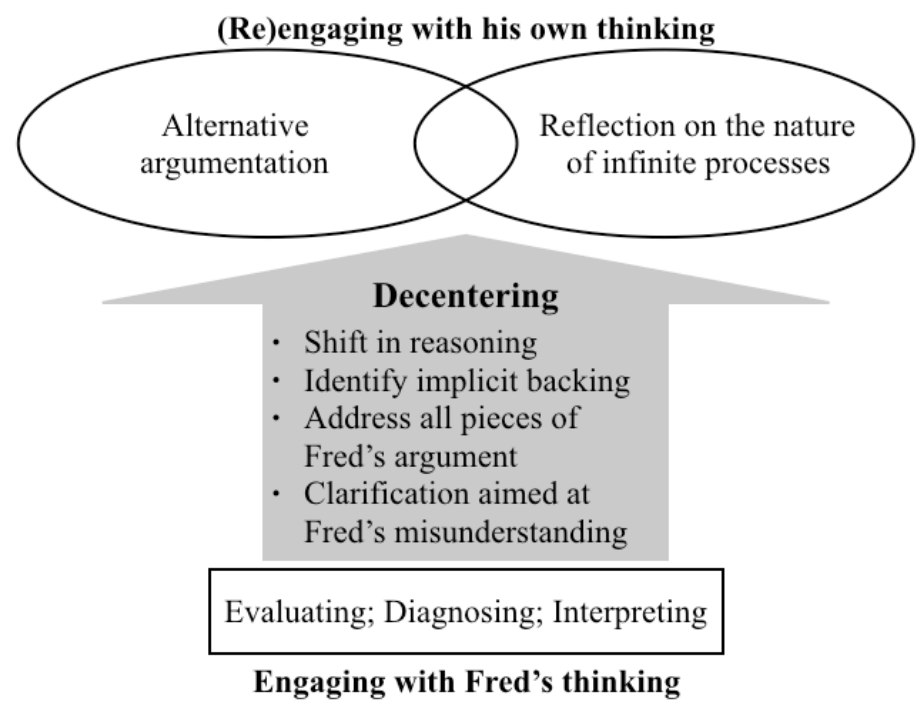

Figure 4: Curtis' productivity from engaging with Fred's reasoning.

\section{CONCLUSION}

In conclusion, we return to classroom social norms and the ultimate role we envision for our framework. We argue that the ways of engaging we observed in these interviews are closely related to particular classroom social norms. The relevant social norms related to engaging in others' reasoning include listening to others' reasoning, attempting to make sense of this reasoning, and indicating agreement or disagreement, with reasons. Moreover, acting in accordance with these norms led, through decentering, to enriched and refined mathematical conceptions and activity. 
The case of Curtis illustrates that decentering is an individual cognitive mechanism triggered by engaging with another's reasoning.

Prior work posits a reflexive relationship between engaging in others' reasoning (i.e., social norms) and individual beliefs. In Figure 1, this relationship coordinates the cells in the top row of the interpretive framework. As far as we are aware, the analysis in this paper is the first to coordinate social norms and individual mathematical conceptions and activity. That is, we provide evidence for a relationship between social norms (upper left hand cell of the interpretive framework in Figure 1) and individual conceptions (bottom right hand cell). This importance of this work lies in coordinating different analytic tools that separately address collective and individual phenomenon. Thus, our framework not only contributes to a nuanced understanding of engaging and decentering with another's reasoning, but also leads to links between individual mathematical conceptions and social activity.

\section{REFERENCES}

Blumer, H. (1969). Symbolic interactionism: Perspectives and method. Englewood Cliffs, NJ: Prentice-Hall.

Cobb, P. (2000). Conducting teaching experiments in collaboration with teachers. In A.E. Kelly \& R.A. Lesh (Eds.), Handbook of research design in mathematics and science education (pp. 307 - 334). Mahwah, NJ: Lawrence Erlbaum Associates.

Cobb, P., \& Yackel, E. (1996). Constructivist, emergent, and sociocultural perspectives in the context of developmental research. Educational Psychologist, 31, 175-190.

Design-Based Research Collective (2003). Design-based research: An emerging paradigm for educational inquiry. Educational Researcher, 32(1), 5-8.

Hershkowitz, R., Tabach, M., Rasmussen, C., \& Dreyfus, T. (2014). Knowledge shifts in a probability classroom: A case study of coordinating two methodologies. ZDM - The International Journal on Mathematics Education, 46(3), 363-387.

Jacobs, V. R., Lamb, L. L., \& Philipp, R. A. (2010). Professional noticing of children's mathematical thinking. Journal for Research in Mathematics Education, 41(2) 169-202.

Kieran, C., \& Dreyfus, T. (1998). Collaborative versus individual problem solving: Entering another's universe of thought. In A. Olivier \& K. Newstead (Eds.), Proceedings of the $22^{\text {nd }}$ International Conference of the Psychology of Mathematics Education, Vol. III (pp. 112-119). Stellenbosch, South Africa: PME.

Lampert, M. (1990). When the problem is not the question and the solution is not the answer: Mathematical knowing and teaching. American Educational Research Journal, 27(1), 29-63.

Mamolo, A. \& Zazkis, R. (2008). Paradoxes as a window to infinity. Research in Mathematics Education, 10(2), 167-182. 
National Council of Teachers of Mathematics (NCTM) (2000). Principles and standards for school mathematics. Reston, VA: Author.

National Governors Association Center for Best Practices \& Council of Chief State School Officers (2010). Common core state standards for mathematics. Washington, DC: Authors.

Núñez, R. (1994). Cognitive development and infinity in the small: paradoxes and consensus. In Proceedings of the Sixteenth Annual Conference of the Cognitive Science Society (pp. 670-674). Hillsdale, NJ: Lawrence Erlbaum Associates.

Rasmussen, C., \& Stephan, M. (2008). A methodology for documenting collective activity. In A. E. Kelly, R. A. Lesh, \& J. Y. Baek (Eds.), Handbook of design research methods in education: Innovations in science, technology, engineering, and mathematics learning and teaching (pp. 195-215). New York: Routledge.

Steffe, L. P., \& Thompson, P. W. (2000). Interaction or intersubjectivity? A reply to Lerman. Journal for Research in Mathematics Education, 31(2), 191-209.

Stephan, M., \& Whitenack, J. (2003). Establishing classroom social and sociomathematical norms for problem solving. In H. Schoen \& R. Charles (Eds.), Teaching mathematics through problem solving: Grades 6-12 (pp. 149-162). Reston, VA: National Council of Teachers of Mathematics.

Strauss, A., \& Corbin, J. (1998). Basics of qualitative research: Techniques and procedures for developing grounded theory (2nd ed.). Thousand Oaks, CA: Sage Publications.

Tabach, M., Rasmussen, C., Hershkowitz, R., \& Dreyfus, T. (2015). First steps in reinventing Euler's method: A case for coordinating methodologies. Ninth Conference of European Research in Mathematics Education (CERME9).

Teuscher, D., Moore, K. C., \& Carlson, M. P. (2015). Decentering: A construct to analyze and explain teacher actions as they relate to student thinking. Journal of Mathematics Teacher Education, 1, 1-24.

Toulmin S. (1969). The uses of arguments. Cambridge: Cambridge University Press.

von Glasersfeld, E. (1995). Radical constructivism: A way of knowing and learning. Bristol, PA: Falmer Press.

Yackel, E., \& Cobb, P. (1996). Sociomathematical norms, argumentation, and autonomy in mathematics. Journal for Research in Mathematics Education, 27, 458-477.

Yackel, E., \& Rasmussen, C. (2002). Beliefs and norms in the mathematics classroom. In G. Leder, E. Pehkonen, \& G. Toerner (Eds.), Beliefs: A hidden variable in mathematics education? (pp. 313-330). Dordrecht, The Netherlands: Kluwer. 